\title{
Saudação do Diretor-Geral do D.A.S.P.
}

\section{F oi a seguinte a saudação do Diretor-Geral, Dr. João Guilherme}

DE ARAGÃo, proferida por ocasião da visita do Presidente da República a êste Departamento.

\section{Scnhor Presidente}

Vive hoje o D.A.S.P. seu mais transcendente momento histórico ao comemorar o transcurso do XXI aniversário de fundação, com a presença de Vossa Excelência, de personalidades integrantes dos Podêres da República, de Chefes de Missão Diplomática de países com que a instituição mantém intercâmbio de assistência técnico-administrativa; de ex-dirigentes que, desde o início, deram lustre e renome ao Departamento.

Por economia de tempo, fujo a digressões retrospectivas. Mas não posso deixar de assinalar que, desde o histórico Decreto-lei $\mathrm{n}^{\circ} 579$, de 30 de julho de 1938, o D.A.S.P., em vinte e um anos de existência, passou por tıês períodos característicos de atividade : no primeiro período, de 1938 a 1945 , a instituição irrompe numa atividade ostensivamente inovadora e renovadora dos métodos tradicionais da ação administrativa; racionaliza a elaboração da proposta orçamentária; cria, então, um «esprit de corps», ádmirável; introduz o sistema do mérito; dá realidade àqueles principios de renovação inscritos na Lei $n .^{\circ} 284$, de 1936 , hoje de especial significado histórico. O segundo periodo, espécie de antítese do primeiro, é o que se inicia com - Decreto-lei n..$^{\circ}$ 8.323-A, de 1945, que mutilou a instituição, felizmente, apenas em sua estrutura formal, e é marcado por algumas investidas tendentes a diminuir e até mesmo a eliminá-la, sob o pretexto de se afigurar órgão de origem ditatorial, insustivel, portanto, de bem servir à democracia. O terceiro periodo de reafirmação e consolidação institucional do D.A.S.P. - seja-me permitido afirmá-lo alto e bom som, é o que se inicia com o Governo de Vossa Excelência e se poderá caracterizar como desmentido categórico ao preconceito de origem demagógica, segundo o qual nosso Departamento é uma instituição antidemocrática. A Vossa Excelência coube demonstrar que o D.A.S.P. não é apenas útil mas necesşário à democracia brasileira; Vossa Excelência veio dar, por assim dizer, essência democrática à instituição, conservando-a integra no desempenho de suas relevantes finalidades de origem.

Diretor-Geral do D.A.S.P., no Govêrno de Vossa Excelência, venero, dentro dos meus antecessores, o grande fundador do D.A.S.P. mas não posso deixar de considerar, como heróis, os que, a partir de 1945, dirigiram 
brilhante e denodadamente a instituição através «do caminho da sobrevivência», para usar a expressão famosa de após guerra, criada por CHARLES VogT.

Agora estamos em terra firme. Desde 1956, está vivendo o D.A.S.P. seus maiores dias de triunfo democrático. É que, ao assumir o Govêrno da República, Vossa Excelência trouxe consigo amplo programa de empreendimentos públicos e o propósito de moralização administrativa, abrangendo a regularidade na gestão de dinheiros públicos e o saneamento da administração de pessoal. Quanto ao primeiro aspecto, herdara o Govêrno compromissos inevitáveis, decorrentes de leis de aumento de vencimentos, no montante superior a trinta bilhões de cruzeiros. Então de ordem de Vossa Excelência, pôs em prática o D.A.S.P. um regime de disciplina de gastos públicos consubstanciado na aprovação prévia de programas de trabalho por unidade administrativa, e na elaboração de plano de contenção de despesas. Tornavase, assim, possivel concentrar maior soma de recursos nos empreendimentos seletivos consignados nas metas governamentais. Em 1959 e 1960, a disciplina de gastos públicos deverá comportar-se nos limites dos planos de estabilização financeira tendo em vista as medidas adotadas pelo Govêrno.

Relativamente ao saneamento da administração de pessoal, a ação do D.A.S.P., por determinação de Vossa Excelência, tem sido, sem exagêro,

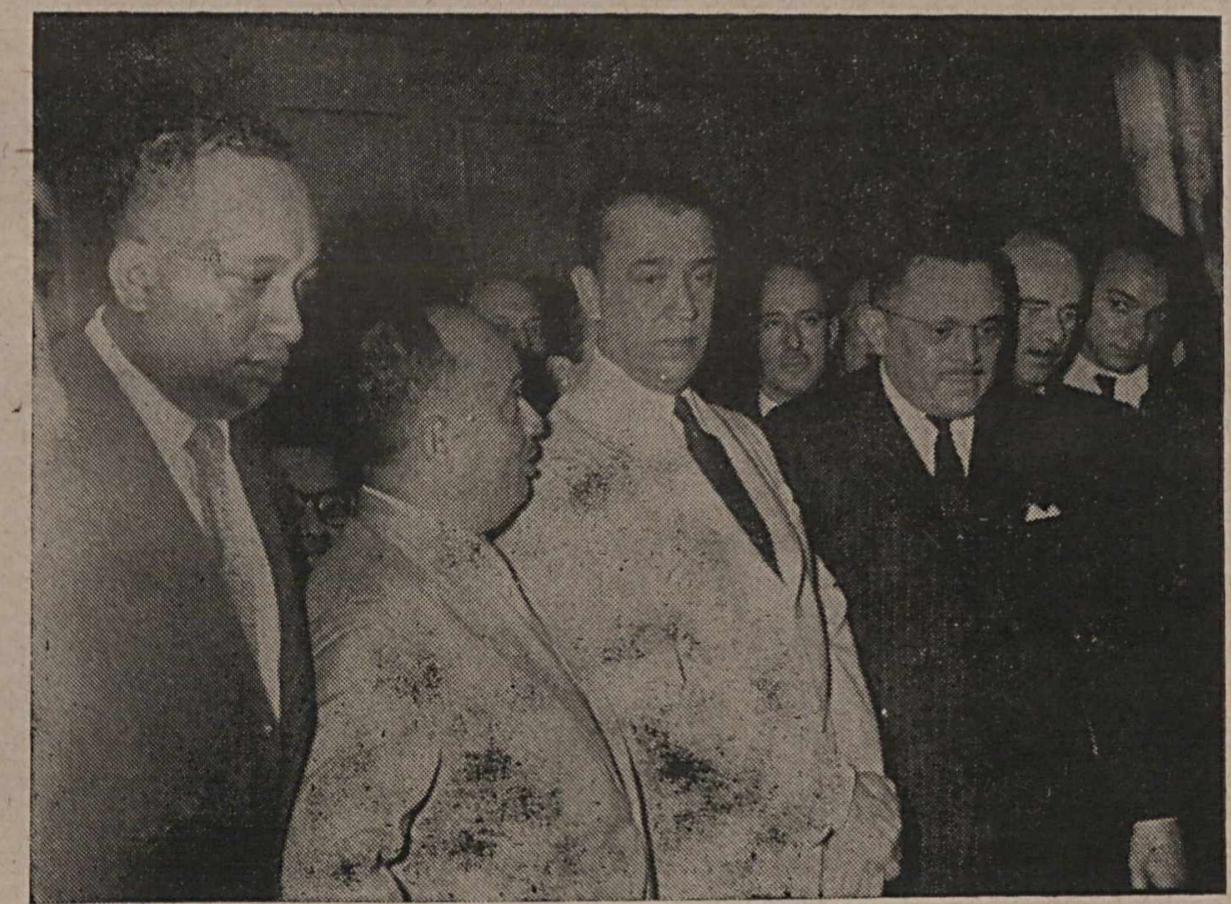

Flagrante do momento em que o Presidente da República era recebido pelo Diretor-Geral do D.A.S.P., Sr. Jõ̃o Gull herme dE ArAGÃo, vendo-se, ainda, o Ministro Sebastião PAes de Almeida, titular da pasta da Fazenda 
hercúlea. Para aplicação da Lei n. 2.745-56, mais de 60 quadros de pessoal das autarquias foram desdobrados em 1956, continuando o Departamento na revisão sistemática de vários outros. Hoje é possivel identificar, na sua integralidade, o vulto das despesas orçamentárias com o funcionalismo ativo e inativo, civil e militar. Quanto ao aspecto numérico é sabido quanto tem sido rigoroso o Govêrno em limitar as admissões de pessoal, chegando a extinguir mais de 35 mil cargos e funções no serviço público. Expandiram-se de modo surpreendente as atividades administrativas de recrutamento, seleção e aperfeiçoamento de pessoal. A Escola de Serviço Público, fundada no Govêrno de Vossa Excelência, tem hoje mais de dois mil alunos, em todo o país, dando assim o exemplo da penetração democrática da função pública. Está funcionando o Curso de Técnica de Administração em regime de acôrdo com - Ministério da Educação. A mesma Escola mantém acôrdos com a Universidade do Rio Grande do Sul e de Minas e agora, de acôtdo com o programa unificado de ensino, a administração pública está na perspectiva de alargar ainda mais o seu âmbito de ação.

Nesse dominio cumpre mencionar a assistência técnica prestada pelo Ponto IV, em que tomam parte, também, entidades educacionais ou ligadas

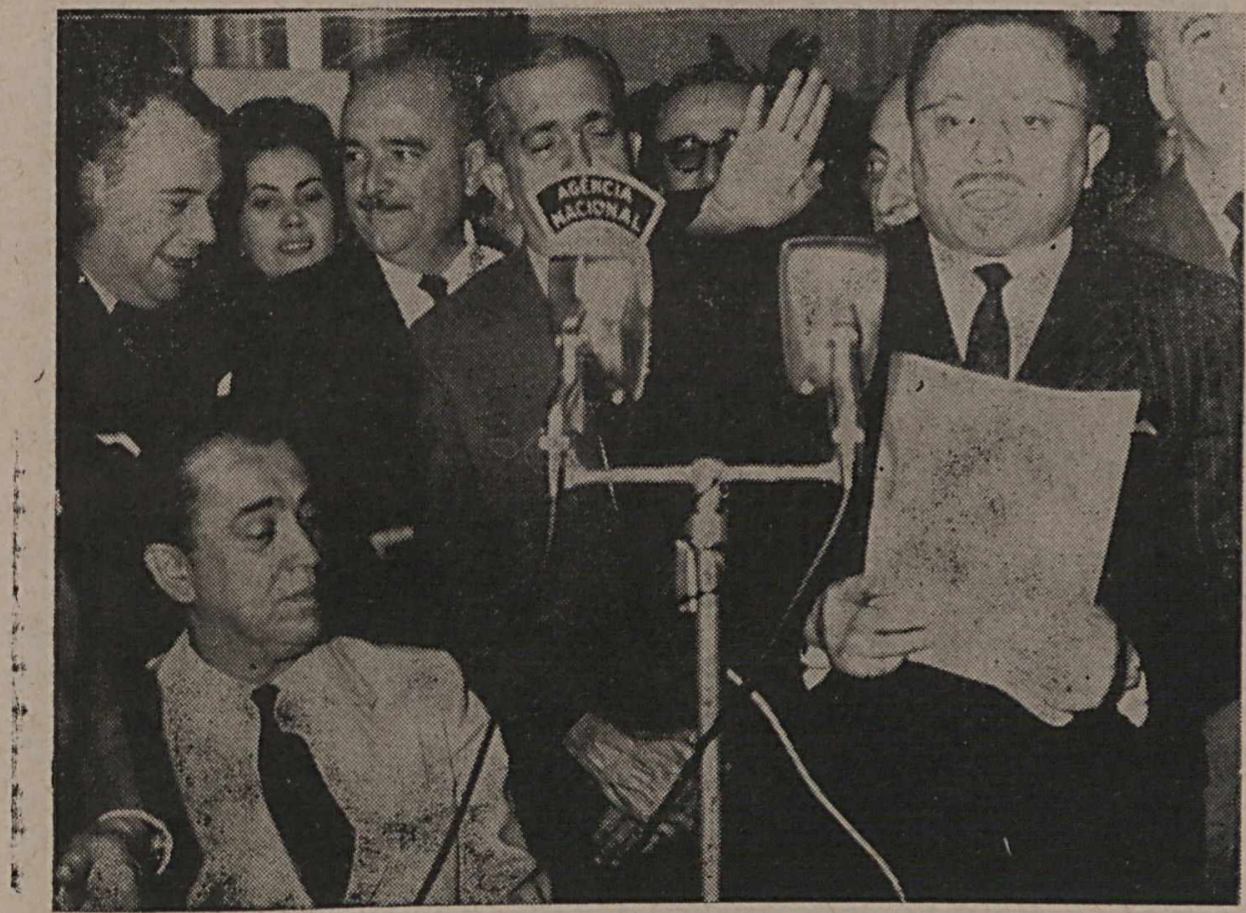

Proferindo a saudação ao Presidente da República, o Sr. JoÃo Gumlherme de Aragđo, Diretor-Geral do D.A.S.P., agradece em nome dos servidores dêste Departamento a presença do Presidente Juscelino KubItSCHEK, vendo-se ainda os Ministros Fernando Nóbrega, do Trabalho, CorrêA DE Melo, da Aeronáutica, Mário Meneghetri, da Agricultura, Alóisio Napoleão de Freitas Rêgo, Chefe do Cerimonial da Presidência da República, e Coronel Nélio Cerqueira Gonçalves, Oficial de Gábinete do Presidente da República 


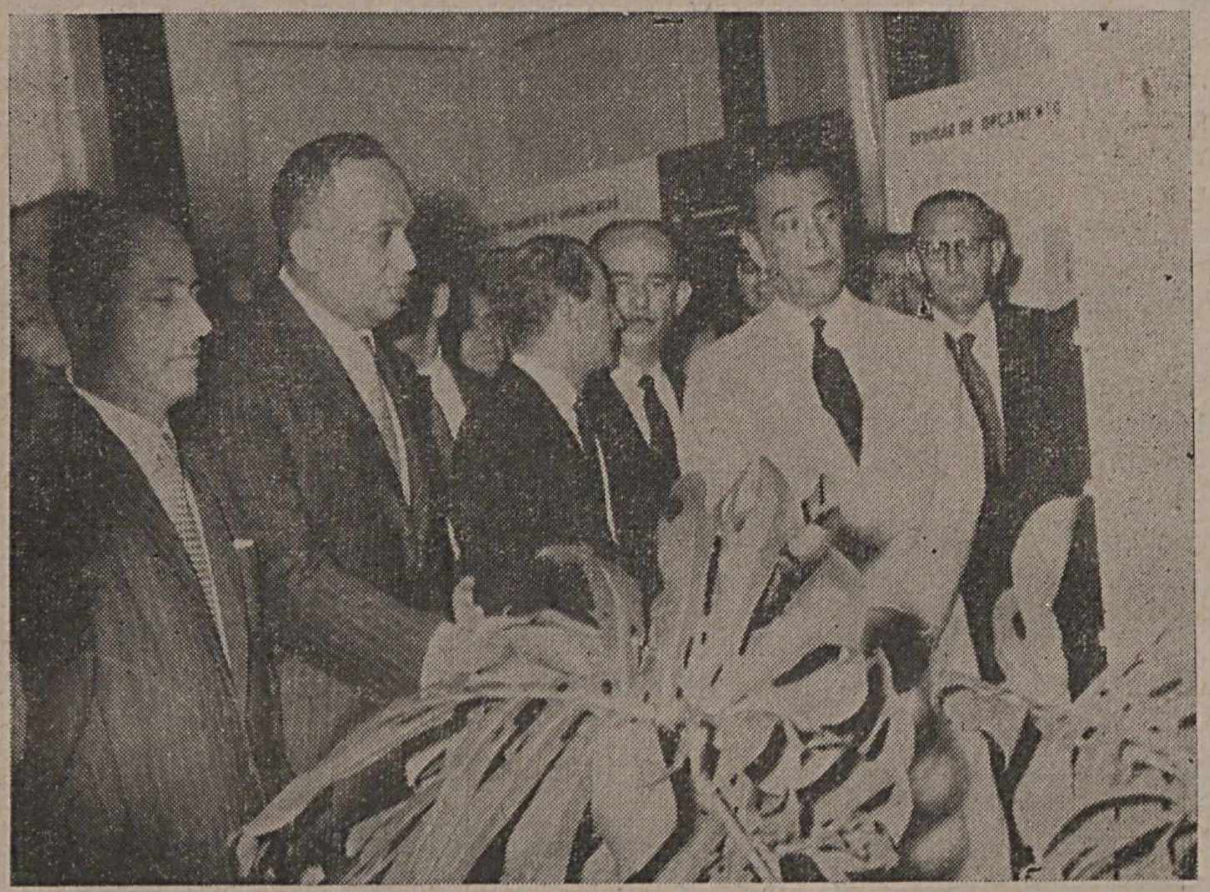

Outro aspecto da visita do Presidente da República ao D.A.S.P., quando o chefe do Govêno examinava a Exposição Comemorativa do $21^{\circ}$ aniversário da instituição, em companhia do Ministro Sebastião Paes DE AlmeIda, titular da Pasta da Fazenda, Oswaldo Penido, Subchefe do Gabinete Civil do Presidente da República, e, prestando informaçóes, os serhotes Manoel Caetano Bandeira de Mello, Diretor do Serviço de Documentação do

D.A.S:P., e Lucílıo Briggs, Chefe do Escritório Técnico da Cidade Universitária

à administraçäo, entre elas a Escola de Serviço Público, possibilitando a formação de pessoal qualificado, nos quadros de servidores da União.

No programa de treinamento em curso, nos diversos setôres do Ponto IV, já foram enviados aos Estados Unidos 1.100 bolsistas, estando prevista a ida de mais de 264 até março do próximo ano.

Essas atividades tendem a ampliar-se cada vez mais, em face da recente criação do Escritório Técnico da representação brasileira junto ao Ponto IV, visando a aperfeiçoar a coordenação dos diversos projetos, e que já se acham em pleno funcionamento no D.A.S.P.

Não posso deixar de realçar a relevante missão que Vossa Excelência nos deferiu ao nos incumbir de planejar e executar a transferência da admi nistração federal para Brasília, obra do século, como recentemente a denominou um dos seus ilustres visitantes. A êste respeito, o Grupo de Trabalho tem sido de operosidade que honra o espirito de nossos servidores civis e militares. Seria longo e impróprio, neste momento, mencionar os indices de nossas atividades sob o Govêrno de Vossa Excelência.

E ao terminar, não fujo à regra de pedir. O D.A.S.P. também pleiteia, Senher Presidente. É que nos consideramos, os atuais componentes do «staff» 
daspiano, como os últimos abencerragens da instituição. É necessário que continue a raça dos crentes da administração. Cumpre renovar-lhe os quadros, progressivamente desfalcados de pessoal. Necessário se torna prosseguir na politica de aperfeiçoamento de servidores no estrangeiro. Se o D.A.S.P. vem oferecendo êsse espetáculo de rendimento e eficiência, tal se deve ao fato de que no seu atual «staff» prepondera a atuação de servidores que se especializaram no exterior, através dos programas de aperfeiçoamento. Neste sentido já realizamos estudos cujos resultados oportunamente submeteremos a Vossa Excelência, para as providências que merecerem. Por fim, quero transmitir a Vossa Excelência a homenagem dos servidores do D.A.S.P. pela alta distinção que nos conferiu ao participar das comemorações do vigésimo primeiro aniversário desta Casa. Quanto ao mais, dirá esta pequena e singela amostra das atividades do D.A.S.P. em seu Govêrno. Ela representa o esfôrço da equipe de técnicos, desenhistas, arquitetos, decoradores do D.A.S.P. Até as plantas, que a ornamentam, vieram da Cidade Universitária, onde foram cultivadas, por servidores nossos! Êsse, sim, é o verdadeiro nacionalismo.

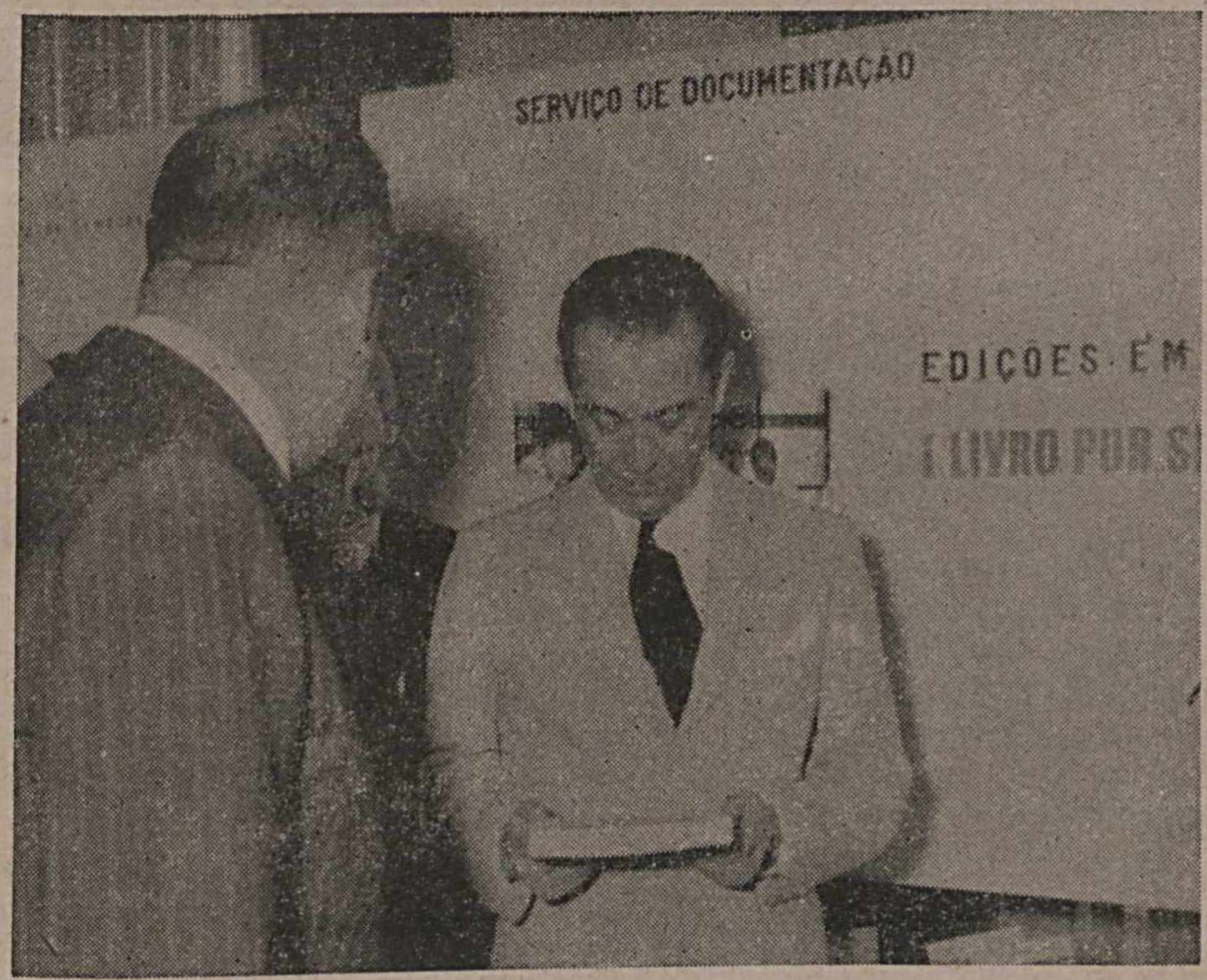

Na foto, o Presidente da República, St. Júscelino KuBrTsCHeK, no momento em que examinava de perto as publicaçóes editadas pelo Serviço de Documentaşão, sendo acompanhado pelo Diretor-Geral do D.A.S.P., Sr. Jo Ão Guilherme de Arag̃̃o e pelo Diretor do Serviço de Documentação, St. Manoel Bandetra de Mello 